\title{
The Regulation of Gambling at European Level. The Balance to be Found ${ }^{*}$
}

\author{
Alan Littler** \\ Published online: 17 August 2007 \\ (C) ERA 2007

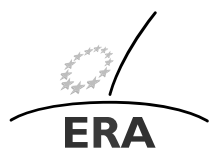 \\ EUROPÄISCHE RECHTSAKADEMIE \\ ACADEMY OF EUROPEAN LAW \\ ACADEMIE DE DROIT EUROPEEN \\ ACADEMIE DE DROIT EUROPEEN \\ ACCADEMIA DI DIRITTO EUROPEO
}

\begin{abstract}
This article seeks to illustrate some of the balances which need to be reached in gambling regulation in the context of the internal market. Such balances are to be found at both the national and European levels. Although the regulation of gambling is currently a national competence, Member States have to consider the impact of the case-law of the European Court of Justice. Consequently the balance of interests which Member States seek to achieve at national level must be striven for in a manner compatible with Community law. This is a balancing exercise in itself. Further, cross-border consequences arise from nationally-oriented approaches, offering both possible solutions and problems for the regulation of gambling in the European Union.
\end{abstract}

Keywords Free movement of services $\cdot$ Gambling

\section{Introduction}

Each Member State of today's European Union has an approach of its own to the regulation of gambling and for the foreseeable future this is likely to remain so. Debates regarding gambling and the regulation thereof within Member States, have,

\footnotetext{
Alan Littler

Tilburg Law and Economics Center (TILEC)

Faculty of Law, Tilburg University

Postbus 90153, 5000LE Tilburg, The Netherlands

e-mail: A.D.Littler@uvt.nl
}

\footnotetext{
*) This article is based on the presentation given by the author at the ERA conference The Future of Gambling in the Internal Market: the Demise of State Monopolies? held in Trier on 8-9 February 2007.

**) The author's thanks are expressed to Professor Cyrille Fijnaut for his useful comments. Responsibility for any errors remains that of the author.
} 
until relatively recently, been of a wholly national nature. Yet with the ever expanding scope of the internal market, gambling has become a significant topic of debate at European Union level, undoubtedly spurred on by the interaction of national laws with primary Community law. No longer is the discussion of the regulation of gambling within Member States wholly national. Rather, it must take into account the requirements of Community law.

In their approaches to regulating gambling, many governments have sought to balance the human desire to gamble with the negative consequences associated with gambling, which principally relate to addiction, crime and fraud. National policies usually regulate the quantity and quality of the gambling supplied. Thus, some forms of gambling may be prohibited or the number of gambling opportunities may be limited. Where the provision of gambling opportunities is permitted, two broad approaches are used to ensure the quality of the gambling services; either the use of a state-owned body with a monopoly position, or a licensing regime with a supervisory and enforcement mechanism. Frequently, national regulatory regimes distinguish between different forms of gambling on the basis of a range of factors, including the addictiveness of a particular form of gambling or the extent of criminal involvement therein.

To date, the European interest in this field has concentrated upon the compatibility of these restrictions with primary Community law and the extent to which the internal market should extend to gambling. The Europeanisation of this debate began in the 1990s with a study by the European Commission which led to the European Council concluding that, on the basis of the principle of subsidiarity, Brussels should desist from becoming involved in the regulation of this sector. ${ }^{1}$ Nevertheless a series of cases has come before the European Court of Justice, something which has naturally led to a debate concerning the relationship between gambling and primary Community law. ${ }^{2}$

The balances which Member States have sought to attain at the national level now have to be balanced with the requirements of the internal market, insofar as these requirements are deemed applicable to gambling. However, even without any Community secondary legislation or explicit competence in this field, cross-border gambling occurs and the activities of gambling providers have cross-border implications at Community level, a point which will be discussed later in this article. Three necessary balancing exercises are thus apparent; firstly that which national legislation strives for; secondly that between national gambling regulation and European Community law; and thirdly balancing the implications of national gambling providers in the internal market context.

Uncertainty prevails in various guises and this article will be dedicated to illustrating some of the balancing acts which national gambling providers seek to achieve when upholding the balance which national legislation establishes. Furthermore, such

\footnotetext{
1) European Commission, Gambling in the Single Market - A Study of the Current Legal and Market Situation, 1991 and European Council, Conclusions of the Presidency, Edinburgh, 11 and 12 December 1992 (DOC/92/8, 13.12.1992).

2) See Case C-275/92 Schindler [1994] ECR I-1039; Case C-124/97 Läärä [1999] ECR I-6067; Case C-67/98 Zenatti [1999] ECR I-7289; Case C-6/01 Anomar [2003] ECR I-8621; Case C-243/01 Gambelli [2003] ECR I-13031; Case C-42/02 Lindman [2003] ECR I-13519; and Joined Cases C-338/04, C-359/04 and C-360/04 Placanica, judgment of 6 March 2007 (not yet reported).
} 
balancing acts will be viewed in the light of the requirement arising from the case-law of the European Court of Justice that national gambling policies be consistent and systematic, so as to illustrate the complexities involved in complying with the currently unclear requirements of the case-law. Finally, the need for a degree of balance to be found in the cross-border context of the European Union will be highlighted. This will lead to a consideration of the elements which a regulatory framework would need to include so to achieve these balances.

In achieving the foregoing, this article will take the following six steps. First, an overview of the complexity of the regulatory environment in the European Union regarding gambling will be given, inasmuch as it arises from a fragmented approach to a common issue. This will be followed secondly by a brief discussion of the principal case-law. Thirdly, the attempts by national providers to balance the requirements of national legislation will be assessed in view of the requirements case-law of the European Court of Justice. Two providers will be looked at for illustrative purposes; Svenska Spel of Sweden and Camelot of the United Kingdom. Issues arising due to the internal market context will be discussed as a fourth step; followed by the fifth step of examining the potential for national concerns regarding tax revenues to cloud the debate. In conclusion, a possible framework for future discussions will be considered.

\section{A Complex and Fragmented Situation}

Taking an overall view, the regulation of gambling within the European Union would appear extremely fragmented due to the virtually unlimited national competence to regulate gambling activities. The complexity of the web of national laws has been exacerbated by the impact of the internet; as a means of communication over a distance, the internet has broken down barriers between different jurisdictions. These two phenomena will be discussed further.

\subsection{Numerous jurisdictions}

With the entry of Bulgaria and Romania into the European Union in 2007, 27 different national gambling jurisdictions now exist. However, it would be inaccurate to state that 27 different jurisdictions regulate gambling. In some Member States certain aspects of gambling regulation are the responsibility of regional levels of government, such as the German Länder as illustrated by the State Lottery Treaty ${ }^{3}$ and the Spanish comunidades autónomas (autonomous communities). ${ }^{4}$ Additionally, local authorities may play a role, with regards to authorising the location of slot machines and casinos for example. A recent and topical example of this has been the willingness of United Kingdom local authorities, such as Blackpool Council and Manchester City Council, to licence casino operations in their area under the Gambling Act

\footnotetext{
3) The Staatsvertrag zum Lotteriewesen in Deutschland has regulated German gambling law since July, 2004. See Arendts/Hambach [1], p. 466.

4) For an introduction to the role of the Spanish autonomous communities in the regulation of gambling see Guilayn [6], p. 485-488.
} 
2005. From a Community law perspective, gambling regulation is clearly fragmented amongst the Member States and their sub-national authorities. Consequently, the potential for conflict to arise between Member States themselves and with regards to Community law is immense.

As will become evident during the following discussion of the case-law, member state attempts to regulate gambling can amount to restrictions of the free movement of services and the freedom of establishment. While justifications for such restrictions may apply in specific cases, the manner in which Member States approach the regulation of gambling would appear to lend itself to restricting these two freedoms. Broadly speaking, Member States take one of two approaches: they either impose a prohibition on gambling or a specific form of gambling, subject to a limited exception; ${ }^{5}$ or a licensing regime is adopted, and frequently the number of available licences is restricted. ${ }^{6}$ Furthermore, in some Member States licences can only be issued if the would-be provider has a legal presence within that target Member State. In some Member States gambling, or a particular form of gambling such as lotteries, is provided by state-owned companies ${ }^{7}$ while in others the single licence-holder enjoys a monopolistic position, although whether there would have been a non-discriminatory competition for the licence - and hence the market - depends upon the tender procedure used. While a highly-regulated gambling regime is not per se in contravention of Community law, the arbitrary exclusion of suppliers established in other Member States entails that the regulatory regimes do not have the capacity to recognise similar regulatory objectives and standards which apply within other European Union jurisdictions.

\subsection{Impact of Long-Distance Communication}

The clash between different jurisdictions has been facilitated by the use of longdistance communication technology, principally the internet, to supply gambling services. With the advent of the internet, and high levels of internet penetration, the cross-border supply of gambling services has become increasingly accessible to an increasingly wide population base. Gambling via the internet overcomes many of the inconveniences which apply to offline gambling products, such as the time and expense it would take residents of one Member State to visit another Member State to take advantage of the availability of casinos. ${ }^{8}$ Consequently, the different approaches

\footnotetext{
5) This breakdown of Member States has been taken from: Swiss Institute of Comparative Law [14]. These member states are Austria, Belgium, Cyprus, Denmark, Finland, France, Germany, Greece, Ireland, Luxembourg, the Netherlands and Slovakia (paragraph 3.1.1).

6) This is the case in Austria, Belgium, the Czech Republic, Denmark, Estonia, Finland, France, Germany, Greece, Hungary, Ireland, Italy, Latvia, Lithuania, Luxembourg, Malta, the Netherlands, Poland, Portugal, Slovenia, Spain and the United Kingdom (ibid., Swiss Institute of Comparative Law, paragraph 3.1.2). The number of licences which a Member State makes available is not always subject to a limit, e.g., licences for bookmakers offices under the UK's Gambling Act 2005.

7) Ibid. See Swiss Institute of Comparative Law, paragraphs 3.1.3 and 3.1.4.

8) One example is that of Dutch residents who, before the advent of Holland Casino operations in 1976, travelled to Belgian casinos located in Blankenberge, Oostende and Spa. Given the accessibility of internet gambling for those with a home internet connection, internet gambling may constitute an attractive alternative even for those who live in the vicinity of offline gambling opportunities, such as bingo halls, casinos or sports betting shops.
} 
of the nationally focussed Member States' regulatory regimes are more likely to come into contact with each other. This can occur in a number of ways, the most obvious of which being business-to-consumer whereby the gambling offered by a provider in Member State A is accessed by a resident of Member State B.

However, the internet also facilitates business-to-business communications, thus making it easier for providers to access other national markets through the use of local agents, a model which will is seen in the case-law of the European Court of Justice. It is often expected that current secondary legislation relating to distance selling and e-commerce will ease the differences between the various national regimes. ${ }^{9}$ Yet cross-border gamblig is not assisted by such legislation, and in any event, in the context of the internal market gambling requires policy issues to be determined which secondary legislation not specifically addressed at gambling does not address.

\section{Case-law of the European Court of Justice}

Gambling-related case-law first surfaced in the European Court of Justice in 1994. In Schindler, ${ }^{10}$ the European Court of Justice was faced with a preliminary question from a United Kingdom court concerning the importation of German lottery tickets in contravention of the then-total prohibition of large-scale lotteries in the United Kingdom. The Court of Justice considered that the prohibition of the importation of lottery tickets amounted to an infringement of Article 49 of the EC Treaty. Gambling was thus viewed as a service within the context of European Community law. Since the prohibition in question amounted to an indistinctly applicable measure, the European Court of Justice considered whether any justifications for the prohibition could be found under the 'rule of reason', as applicable in other cases concerning Article 49 of the EC Treaty. ${ }^{11}$ The Court of Justice referred to the 'peculiar nature' of lotteries, which it considered resulted from the moral, religious and cultural aspects of lotteries; the associated risk of crime or fraud; and the fact that lotteries amounted to an incitement to spend which has the potential to lead to damaging consequences for the individual and society. Member States were left with a considerably large margin of discretion in which they could restrict the supply of cross-border gambling services. If one could talk of a freedom to provide gambling services at this stage, it would have been a very weak freedom.

The prerogative of Member States remained unchallenged by the cases of Läärä and Zenatti. ${ }^{12}$ Interestingly the Court considered in Lä̈̈rä that the assessment of restrictions on gambling in one Member State cannot be influenced by what is permitted in other Member States. For as long as this field remains unharmonised, the Court

\footnotetext{
9) Directive 97/7/EC of 20 May 1997 on the Protection of Consumers in respect of Distance Contracts, OJ L144 of 4 June 1997, p.19 and Directive 2000/31/EC of 8 June 2000 on certain legal aspects of information society services, in particular electronic commerce, in the Internal Market ('Directive on electronic commerce'), OJ L178 of 17 July 2000, p.1.

10) Case C-275/92, supra note 2.

${ }^{11)}$ In Case 120/78 Cassis de Dijon [1979] ECR 649 the European Court of Justice developed the notion of the 'rule of reason' via which Member States could justify non-discriminatory restrictions on the free movement of goods on the basis of objective justifications. An equivalent notion for services has been developed, following Case 33/74 van Binsbergen [1974] ECR 1299.

12) Case C-124/97 and Case C-67/98, supra note 2.
} 
considered that national restrictions should be considered only in the light of national objectives. ${ }^{13}$ This contrasts sharply with earlier case-law regarding double regulatory burdens, such as that of Webb. ${ }^{14}$ Here the European Court of Justice encouraged comparative inquiries as to the justification and proportionality of the restriction complained of, vis-à-vis the requirements of the home Member States.

Following Zenatti, Straetmans commented that Member States were able to 'exercise value judgments ... within the very wide margin of discretion accorded to them by the Court.' 15

The subsequent case of Gambelli ${ }^{16}$ was viewed as setting the outer limits of the discretion enjoyed by Member States. ${ }^{17}$ In contrast to earlier cases, the European Court of Justice did not rule whether it considered the restriction to be indistinctly applicable but gave the referring court relatively detailed guidance to assess the nature of the national restriction. ${ }^{18}$

Consequently a European-based criterion, in the widest sense of the term, for assessing restrictive national measures took shape. First, the European Court of Justice explicitly brought the Gebhard ${ }^{19}$ line of case-law into the gambling sector, stating that measures "must be justified by the imperative requirements in the general interest, be suitable for achieving the objective which they pursue and not go beyond what is necessary in order to attain it." Secondly, and for the first time in the gambling area, this was combined with, specific references for the need to take into consideration the regulatory burdens which the supplier already faces in the Member State of establishment. ${ }^{20}$ However, most of the subsequent discussion has concentrated on the requirement that the restrictive measure is part of a policy which "limits betting activities in a consistent and systematic manner". ${ }^{21}$ This is where the balancing act regarding state monopolies and those regulatory models which employ a sole provider arises; the justification of the restriction in the form of a single provider is based upon quantitative restrictions. However, this is not expressed in numerical terms and to a considerable extent it depends upon the policy decisions of the prevailing national governments.

Following this part of Gambelli, national courts have to consider whether any restrictions on the provision of gambling from another Member State are consistent with the manner in which the monopolist, or licensed operator, operates. Thus, if the stated aim of the national restriction is to limit the demand for gambling services due to the dangers associated with gambling, it is difficult to prove that the national policy is consistent, or being complied with in a consistent manner, if the single operator is permitted to advertise heavily and refers to increasing profits as a motivating factor in its annual reports. Not only should this balancing act take place before national courts seized of this issue, but the relevant government ministry or authority should ensure

\footnotetext{
13) Case C-124/97, supra note 2, paragraph 36.

14) Case 279/80 Webb [1981] ECR 3305.

15) Straetmans [10], p. 1001.

16) Case C-243/01, supra note 2.

17) Straetmans [11], p. 1421.

18) Case C-243/01, supra note 2, paragraph 65.

19) Case C-55/94 Gebhard [1005] ECR I-4165.

${ }^{20)}$ Following in the light of Webb, supra note 15 and Case C-272/94 Guiot and Climatec [1997] ECR I-3899.

${ }^{21)}$ Case C-243/01, supra note 2, at paragraph 67.
} 
that the monopolist reflects a consistent and systematic execution of the regulatory regime. $^{22}$

In November 2003, the Court gave its judgment in the case of Lindman, ${ }^{23}$ which, unlike the proceeding cases, did not concern an indistinctly applicable measure but rather the application of Finnish tax law to winnings in a Swedish lottery. However, the European Court of Justice continued in the general direction embarked upon in Gambelli by explicitly referring to the fact that the government parties involved had failed to show that there was a causal relationship between the risks which they cited, and the participation of their residents in gambling offered in another Member State. This raises the question of whether an evidentiary burden has been placed upon Member States when defending restrictive measures.

The latest instalment in this line of case-law, Placanica, ${ }^{24}$ can be considered to reduce the margin of discretion which Member States enjoyed under Schindler. Although the ruling in Placanica deals with a number of issues, the most relevant for this article are those considered under the heading 'licensing issues' ${ }^{25}$ Continuing along the path established in Gambelli, the European Court of Justice recognised that restrictions relating to the combating of crime and fraud can be used as a justification independently of the objective of eradicating the actual number of gambling opportunities. Consequently, a controlled expansion of gambling opportunities was deemed acceptable, and the European Court of Justice noted what this may necessitate 'the offer of an extensive range of games, advertising on a certain scale and the use of new distribution techniques' ${ }^{26}$ There was no intention to curtail the availability of gambling or reduce the propensity of the Italian population to gamble, and consequently no genuine diminution of gambling services needed to occur. However, if the objectives of the national legislation were to only meet unstimulated demand as well as reduce crime and fraud it becomes less clear whether a policy of controlled expansion is permissible, and if so, the extent to which gambling opportunities can be expanded.

Interestingly, the Court also referred to evidence adduced by the Italian government which served to illustrate the significant illegal gambling market in Italy, which the government sought to eradicate. It would thus appear that in the light of Lindman, Member States have accepted that an evidentiary burden exists to justify credibly a restrictive measure. ${ }^{27}$

\footnotetext{
${ }^{22)}$ Holland Casino, the Dutch state-owned casino operator provides an example. In their 2003 Financial Report they stated that '[i]t is expected that gross profits and net company results will further increase in 2004. To guarantee an increase in profits during an economic recession, Holland Casino must continue to reduce its costs.' (Holland Casino, Financieel verslag 2003, p. 14). However, their 2004 Annual Report reflects a change in approach: 'Holland Casino does not pursue a profit maximalisation strategy.' (Holland Casino, Jaarverslag 2004, p. 21).

${ }^{23)}$ Case C-42/02, supra note 2.

${ }^{24)}$ Joined Cases C-338/04, C-359/04 and C-360/04, supra note 2.

${ }^{25)} \mathrm{Ibid}$., paragraphs 50-58.

26) Ibid., paragraph 55 .

27) The EFTA Court provided a further interpretation of Gambelli in a case arising out of the Norwegian government's objective of establishing a sole right to operate slot machine games which would be granted to a state-owned body. Case E-1/06 EFTA Surveillance Authority v Norway, judgment of 14 March 2007 (not yet reported). Arguably the EFTA Court entered into far greater detail in considering justifications for a restriction on the supply of gambling services than the European Court of Justice has done to date.
} 


\section{Case Studies - Sweden and the United Kingdom}

This section aims to provide some insights into the compatibility of two gambling providers with the case-law of the European Court of Justice. Assuming that an operator does not deviate from the objectives of the national gambling regulations, their activities will be an embodiment of that national policy. As the European Court of Justice recalled in Placanica, "... Member States are free to set the objectives of their policy ..." and "... to define in detail the level of protection sought ...". ${ }^{28}$ Consequently, the worthiness or otherwise of the legislative objectives are not called into question, but rather the consistency with which they are executed. Gambling providers who operate in a restricted market have to balance the need to attract customers while not contradicting the reasoning behind the justifications for the national restrictions which are in place. These restrictions arguably provide numerous national providers with a monopolistic position.

Firstly, the objectives of the legislative regime in which the two providers operate will be briefly described. For the second part their attempts in securing the accessibility of their services will be discussed, with particular reference to the use of the internet. At this stage the manner in which the operators balance the objectives of 'their' regulatory regime will be considered in the light of the 'consistent and systematic' requirement of Gambelli as furthered by Placanica.

The two operators which will form the basis of the compatibility discussion are Svenska Spel of Sweden and Camelot of the United Kingdom.

\subsection{The Operators and Their Respective Legislative Regimes}

Svenska Spel is a $100 \%$ state-owned body, and enjoys a monopoly in the provision of lotteries and number games, sports-betting and dog racing, slot machines and the operation of the four Swedish casinos, pursuant to the Lotteries Act and the Casino Act. ${ }^{29}$ The overriding aims of the Lotteries Act are to protect the public from criminal elements as well as the individual from the negative economic and social consequences of gambling. Furthermore, it aims to protect the interests of consumers and control the profits made by lotteries. ${ }^{30}$ As part of its recognition of the negative consequences of gambling, Svenska Spel takes a so-called '100\% preventative approach' towards gambling. Consequently, Svenska Spel states that it aims to ensure that gambling is an enjoyable activity while keeping it within reasonable proportions and avoiding excessive levels of gambling with the associated negative consequences.

In contrast to the Swedish situation, the United Kingdom national lottery operator Camelot, a private company, has been awarded the licence to operate the national lottery and other lottery games pursuant to a competitive tendering procedure. ${ }^{31}$ Having

\footnotetext{
28) Joined Cases C-338/04, C-359/04 and C-360/04, supra note 2, paragraph 48.

29) Ömberg [19]. Lotteries Act (1994:100) and the Casinos Act (1999:335). The Swedish horseracing betting monopoly is held by AB Trav och Galopp (ATG) and public benefit organisations (voluntary organisations) are permitted to hold lotteries and bingo under specific conditions.

${ }^{30)}$ See also the website of the Swedish Gaming Board, Lotterinspektionen at www.lotteriinspektionen.se.

${ }^{31)}$ While there is currently a single national operator, section 1 of the National Lottery Act 1993 makes it clear that there can be numerous lotteries within the 'National Lottery'. However, a licence is awarded for the operation of the National Lottery under section 5, and only one entity can be awarded this 'section 5 licence' at anyone time.
} 
been awarded the licence to run the lottery by the National Lottery Commission, the operator thus holds a legal monopoly for the period of the licence. Competition then exists for the entire market, and once awarded the single licence the operator does not face any competition from similar lotteries for the lottery-playing consumer base. Under the terms of the 1993 National Lottery Act the regulator, the National Lottery Commission, is obliged to ensure that the interests of National Lottery participants are protected while ensuring the greatest possible net returns for the lottery. ${ }^{32}$

In contrast to the Swedish situation, revenue maximisation is a clear legislative objective and consequently the role of the operator is not merely to ensure the protection of players. It can thus be anticipated that activities of a commercial nature which would be 'consistent and systematic' with a restriction on the cross-border provision of gambling services in the United Kingdom would not be so in Sweden where policy objectives do not specifically concern achieving a maximum number of ticket sales.

\subsection{Ensuring Accessibility While Complying with the Case-Law}

Turning to the second part of the case studies section, the manner in which the two operators ensure the accessibility of their gambling products will be examined in the light of the European Court of Justice's case-law. However, before doing so, the importance of accessibility from a non-legal perspective will be outlined.

Factors which encourage people to gamble, and in some cases lead to gambling addiction, fall into one of two categories; situational characteristics and structural characteristics. Situational characteristics include factors such as the location of the gambling supply while structural characteristics relate to the nature of the game itself, such as the pay-out interval. ${ }^{33}$ A key situational characteristic is the accessibility of the gambling service; the more accessible the supply of a gambling product is, the wider the audience will be. Furthermore, increased accessibility is considered to increase the uptake of gambling services, and has the potential to increase problem gambling - since those who may not have otherwise gambled may do so, and the formerly reasonable levels of gambling engaged in by some persons may become excessive. ${ }^{34}$

Evidently, state operators' services have to be accessible otherwise residents will be discouraged from using such services. This applies to both offline and online forms of gambling: if the state-sponsored service is offered in too few locations or in an unattractive manner, illegal operations will develop. Internet-based gambling is often portrayed as being of potentially greater danger than offline gambling, and so some Member States have accordingly deemed it necessary to permit the incumbent state monopolist to provide online gambling services. While the effects of internet gambling are currently not well documented, ${ }^{35}$ some concerns relate to the internet increasing the accessibility of gambling. Quite simply players are able to access gambling services from the comfort of their home (or office ${ }^{36}$ ) computer. This entails

\footnotetext{
32) Section 4, National Lottery Act 1993.

33) Griffiths [4].

${ }^{34)}$ Griffiths, Parke, Wood and Parke [5].

35) Ibid., p. 1.

${ }^{36)}$ For an account of the increasing availability of gambling in the workplace see Griffiths, Parke, Wood and Parke [5].
} 
several side-effects such as the absence of social checks and balances which are associated with gambling in an offline casino or other environment, and the greater danger that a player's judgment will be suspended. ${ }^{37}$

Yet to what extent should these services be accessible, and - bearing in mind national objectives - to what extent is the degree of accessibility relevant for the caselaw of the European Court of Justice? To elaborate upon this point, the approaches of Svenska Spel to mobile phone based bingo services will be considered.

In its corporate literature, Svenska Spel notes that it is the world's largest bingo operator and offers bingo via mobile phone. ${ }^{38}$ Swedish residents no longer have to go to a bingo-hall to play, but can easily do so while on their daily commute. In such a situation the question arises as to how a national court (or the European Commission) will assess whether the degree of accessibility is consistent and systematic with national policy.

A possible approach could be to consider that offering bingo via mobile phones offers an alternative for Swedish residents who would otherwise take up the services of an offshore unregulated mobile phone bingo supplier. Consequently, by playing with the state operator, Swedish residents are playing in a secure environment and this could be considered as 'capturing' residential demand. Alternatively, if there was no previous mobile phone bingo service in Sweden, it is conceivably arguable that Svenska Spel is diverting residents from other forms of gambling products which may have been offered by an offshore unregulated operator. Without evidence from some sort of market research to show otherwise, it is also possible that there was never a demand for such a service prior to the introduction of Svenska Spel's service. If this cannot be ascertained, does Svenska Spel then overstep an invisible mark and offer a service for which originally there was no demand and could it thus in fact be said to be encouraging gambling?

An answer to the question presumably would require evidence of consumer preferences and the substitutability of different gambling products. This raises the question of whether a state operator can respond to a product development and then offer it itself, or whether it can develop it and offer it before an unregulated supplier attempts to do so. Following Placanica it is arguably more consistent with the case-law for a national operator to take such a 'pre-emptive strike' while maintaining a consistent and systematic gambling policy. As discussed above, the European Court of Justice in Placanica recognised the need for 'an extensive range of games, advertising on a certain scale and the use of new distribution techniques. ${ }^{39}$ However, the objective of the national gambling regime in question was to eradicate the use of betting and gambling activities for criminal and fraudulent purposes and the prevailing policy aimed at drawing players away from offers of this kind.

In contrast, the Swedish legislation places greater emphasis on protecting players from the danger of gambling. While this encompasses limiting crime and fraud, it also entails protecting the population from other negative consequences associated with gambling. Consequently, this could reduce the ability of the Swedish operator to develop a particular form of gambling via a previously unused means of communica-

\footnotetext{
${ }^{37)}$ By using electronic money gamblers may not appreciate the amounts which they are staking.

${ }^{38)}$ Svenska Spel International [13], p. 5.

39) Joined Cases C-338/04, C-359/04 and C-360/04, supra note 2, paragraph 55.
} 
tion if an unlawful source of gambling was not already in existence. Further clarification from the European Court of Justice is required on this point; does the 'use of new distribution techniques' require that those techniques be previously used by unlawful suppliers whom the state operator is attempting to eradicate or may the state operator be the first operator to use those techniques?

Evidently, in the absence of any other source of clarification, the case-law needs to be further explained so as to ensure that Member States are able to determine the margin of discretion available to them in which they can achieve the balance of interest which they deem appropriate.

\section{Internal Market Issues}

As was noted in section two above, the internal market is extremely fragmented insofar as concerns the supply of gambling services. This has the potential to bring about at least two ways in which the need for European Union action to remove imbalances and inconsistencies when gambling occurs in a cross-border multi-jurisdictional environment is illustrated. First, by maintaining nationally-focused regulatory environments Member States do not achieve their own objectives to the greatest extent possible. As an example of this phenomenon, the use of responsible gambling mechanisms will be considered below. Secondly, the principles which underlie national gambling regimes appear to be of limited significance when a national operator acts outside its domestic jurisdiction. This point will be illustrated by the use of databases for betting on football matches.

\subsection{Limitations of a Nationally-Focused Approach}

To counteract concerns regarding the dangers of excessive participation in internet gambling, providers of such services may include certain technical mechanisms in their software to prevent players from playing beyond their means, and ultimately to avoid becoming addicted to such services. Including these mechanisms is especially important for state operators whose regulatory environment seeks to reduce the negative externalities related to gambling. As an illustration of these mechanisms and the associated limitations in the context of the internal market, the internet poker service of Svenska Spel will be used.

Svenska Spel offers internet poker, which includes certain mechanisms which encourage responsible play such as limitations on the amount of time played and money spent. Indeed, to avoid their registered players suspending their judgment and failing to value the money spent on the site actual bank notes are shown. These reflect a coherent and systematic approach to protecting vulnerable players and are positively reflected by some of the early scientific knowledge in the field. ${ }^{40}$

These mechanisms are part of a wider approach operated by Svenska Spel to encourage responsible gambling. The company operates a loyalty card, 'Spelkortet', via which it enters into a dialogue with customers and allows them to set limits to their

\footnotetext{
40) See eCOGRA [2] in which players were found to generally find responsible gambling features on regulated sites to be useful, p. 12.
} 
gambling patterns. ${ }^{41}$ By providing a one-shop solution, arguably the consumer is well protected and cannot avoid responsible gambling mechanisms by simply moving to the site of another nationally licensed provider, because such a provider does not exist.

However, because of the ease of long-distance communication, a Swedish resident can simply switch to another supplier located in another Member State. The Swedish system currently only operates in favour of those with a registered address in Sweden. If similar mechanisms are developed in other Member States and require players to be resident in that Member State, then eventually all markets will be foreclosed and sites will draw only players only from their national jurisdiction. Member Sates not offering state-sponsored or state-regulated forms of gambling will simply deprive their residents of any responsible gambling mechanisms. Moreover, such innovations on the part of operators such as Svenska Spel could offer a blessing in disguise for those in favour of an internal market for cross-border gambling services. If all regulated providers in those Member States where internet gambling is legitimate have to manage such responsible gambling features then maintaining cross-border restrictions on supply would undoubtedly appear disproportionate regarding the national regulatory objectives.

Under the free movement of services and the principle of mutual recognition, boundaries upholding segmented national markets appear unjustifiable. The creation of a European Union-wide registration system and a single responsible-gambling mechanism (such as a loyalty card) would ensure a consistent responsible gambling policy being upheld across the European Union while respecting the freedom to provide services. Consistency would be upheld across the Community which shows the notion of consistency in a new light. The European Court of Justice's rulings address Member States as separate jurisdictions, yet without a degree of co-ordination between them, national policies hardly operate in a consistent and systematic manner when viewed from a Community perspective.

\subsection{National Operators Acting Outside Their Domestic Jurisdiction}

The interaction between gambling and other aspects of European Community law also serves to illustrate the potential for inconsistencies to arise at the Community level, as is evidenced by the use of databases. Currently, state operators are not under a duty to uphold the principles which form the basis of their national regimes when acting outside their domestic jurisdictions. To illustrate this, the refusal of a state monopolist to pay for information regarding football fixtures will be used. Although Svenska Spel was party to the relevant case before the European Court of Justice, many other Member States supported the Swedish operator's position.

In 1999 Svenska Spel refused to pay a fee to the United Kingdom company which was responsible for handling the fixture lists of the English and Scottish professional football leagues ${ }^{42}$ This company drew the lists of matches to be played in the leagues and published this data, which Svenska Spel subsequently used to allow Swedish residents the opportunity to bet on English and Scottish football matches. By declin-

\footnotetext{
${ }^{41)}$ Svenska Spel [12], p. 6.

${ }^{42)}$ Case C-338/02 Fixtures Marketing Ltd [2004] ECR I-10497.
} 
ing to pay the fee requested, Svenska Spel was cutting off a flow of income for the relevant football leagues. The question arose as to whether the relevant fixtures lists benefited from the protection accorded to databases under the Database Directive. ${ }^{43}$ According to the European Court of Justice, they did not. Consequently, state monopoly operators who used this information to offer betting products to their residents and raise money for sports and good causes in their own Member States were no longer required to pay a fee to make up the detriment done to such funding in another Member State. This is in sharp contrast to Svenska Spel's social responsibility report which states that "[t]here is a close connection between Svenska Spel's operations and sports and it is therefore natural that the main beneficiary of our profit is sports for children and youth." ${ }^{4}$

The Gambelli case-law relates only to the domestic activities of state operators. Consequently, while operators such as Svenska Spel may not be legally obliged to pay a fee for fixture lists, this case nonetheless illustrates the discrepancy and imbalance between the aims of state monopolies and their activities outside their home jurisdiction. The question should be asked as to why the sports and good causes of the home Member State should take precedence over those of another Member State. ${ }^{45}$

\section{Taxation Issues}

Another issue inherently connected with the use of and possibly reliance on monopolies for the supply of gambling services is the raising of money for good causes and taxation revenue. Even though governments cannot impose restrictions on the supply of gambling services to protect revenue streams, ${ }^{46}$ the very magnitude of such revenue flows cannot be ignored. On average, European state lottery operators allocate $33 \%$ of their gaming turnover to good causes compared to $3 \%$ for gaming firms. ${ }^{47}$ However, many governments do not adhere to the principle of additionality under which gambling-generated revenues are only spent to fund projects which would otherwise have not received funding. ${ }^{48}$ This was one of the founding principles upon which the National Lottery was introduced in the United Kingdom, for example. However, it has since been eroded with legislation from 1998 diverting funding away from "good causes" and to "innovative projects in health, education and the environment". ${ }^{49}$ Arguably this amounts to a "covert siphoning off of funds from the original Funds for Government projects that should have been met out of taxation." ${ }^{50}$ Following this amendment, $£ 2.4$ bn was contributed to the British Exchequer between 1998

\footnotetext{
43) Directive 96/9/EC of the European Parliament and of the Council of 11 March 1996 on the legal protection of databases, OJ L77 of 27 March 1996, p. 20.

44) Svenska Spel [12], p. 17.

${ }^{45)}$ This issue has been debated in the United Kingdom House of Commons. See the Adjournment Debate led by Jim Sheridan MP 'Football (Gambling Companies)' on 23 January 2007. Daily Hansard, Columns 1395-1399.

46) See Case C-275/92, supra note 2, paragraphs 59-61.

47) London Economics [8], p. 23.

${ }^{48)}$ Ibid., p. 26-27. 56\% of revenues generated by national lotteries went straight into state budgets, with only some of this amount having been earmarked for expenditure on good causes.

49) Section 6, National Lottery Act 1998.

${ }^{50)}$ Lea [7], p. 15.
} 
and 2004. Given the magnitude of these amounts it is possible that some governments have become addicted to lotteries and monopolies, perhaps more so than the players they seek to protect. This should not stand in the way of creating a balanced Community approach to the regulation of gambling, however.

\section{Concluding Remarks}

Currently there is substantial legal uncertainty as to how a Member State which seeks to uphold a restriction must maintain a consistent and systematic gambling policy to justify the restriction in question. As a direct consequence the outer boundaries of what is acceptable for a state monopolist to engage in have become difficult to define. Additionally, the extent of scientific knowledge in this field is limited in the European context, which contributes to the difficulties regarding the justiciability of the issues at hand.

National governments must ensure that policies are consistent and systematic, and national courts may be called upon to assess this, yet a criterion for assessing such policies simply does not exist. Consequently, the manner in which Community law requires Member States to balance their concerns with a restriction on the supply of gambling is unclear. Furthermore, the fragmented internal market delivers imbalances and inconsistencies which limit and possibly contradict national objectives.

It is therefore understandable that many parties involved in this industry are sceptical of deregulation or the explicit transfer of any competences to the European Commission. At the very least the free movement of services jurisprudence and general principles of European Community law must be respected. Yet it is unclear even how this is to be achieved, regardless of any issues involved in heeding the calls of those dreaming of a deregulated or harmonised gambling internal market.

In the light of the ongoing discussions, two points should be realised regarding deregulation and harmonisation. First, deregulation does not entail a lack of regulation. As alluded to by Geradin, deregulation involves a change in the style of regulation and could perhaps be better explained as re-regulation. ${ }^{51}$ State monopolies are not simply removed and the gates left wide open for private operators to act freely. An entirely new regime will be enacted, as has been the case for various sectors which have undergone 'liberalisation', such as telecommunications and electricity. Deregulation of the gambling industry would not have to entail the removal of safeguards against problem gambling and fraud, but rather would incorporate these into a common framework for the European Union. Yet the establishment of any framework for regulating the industry along these lines would require a careful balancing of objectives and a transparent criterion for assessing permitted restrictions.

Secondly, others may talk of harmonisation. While the degrees to which certain activities may be harmonised vary, any subsequent margin of discretion left for Member States over and above minimum standards set could perhaps only codify current case-law. Given the imbalances between Member States' approaches to this sector, it is improbable that a politically acceptable compromise could be reached in the form of a 'harmonisation directive'.

${ }^{51)}$ Geradin [3], p. 182. 
Nevertheless the status quo is unacceptable and a solution needs to be found. Instead of a selection of national courts reaching various interpretations of an unclear criterion and the European Commission launching infringement procedures on an ad hoc basis, legal certainty has to be achieved. From the foregoing discussion, the repercussions of gambling policy are both national and European in nature. An initiative needs to develop which can overcome the current impasse. As long as scientific knowledge on the effects of gambling, particularly internet gambling is lacking in some Member States, the funding of research by the industry would be worthwhile so that a clear portrait of the effects of gambling can be drawn. With a coherent picture of the social and crime related impacts in each Member State the question of whether national regimes and their execution are consistent and systematic, not only in their national context, but also within that of the internal market will be made clearer. $\mathrm{Na}-$ tional balancing exercises would be based upon and illustrated by facts and figures, and thus their assessment in the light of existing case-law would become more accurate. However political will will be needed to overcome the imbalances which arise at internal market level since these issues are not captured by case-law.

\section{References}

1. Arendts, M., Hambach, W.: Germany in: Balestra, M., Cabot, A. (eds.), Internet Gambling Report: An Evolving Conflict Between Technology and Law, St. Charles, River City Group (2005)

2. eCOGRA, Global Online Gambler Report, An Exploratory Investigation into the Attitudes and Behaviours of Internet Casino and Poker Players, Media Summary (2007). Available at www.ecogra.com

3. Geradin, D.: The Opening of State Monopolies to Competition: Main Issues of the Liberalisation Process in Geradin, D. (ed.), The Liberalization of State Monopolies in the European Union and Beyond, Kluwer Law International (2000)

4. Griffiths, M.: Gambling Technologies: Prospects for Problem Gamblers. Journal for Gambling Studies 15(3), 265-283 (1999)

5. Griffiths, M., Parke, A., Wood, R., Parke, J.: Internet Gambling: An Overview of Psychosocial Impacts. UNLV Gaming Research and Review Journal 10(1), 27-39 (2006)

6. Guilayn, A.A.: Spain, in: Balestra, M., Cabot, A. (eds.), Internet Gambling Report: an Evolving Conflict Between Technology and Law, St. Charles, River City Group (2005)

7. Lea, R.: The Larceny of the Lottery Fund, Centre for Policy Studies, London (2006)

8. London Economics, The case for State Lotteries. A Report for the European Lotteries and Toto Association, September 2006

9. Ömberg, J.C.: Nordic gambling markets and the possibilities for state-level control. Journal of Gambling Issues 18, 9-30 (2006)

10. Straetmans, G.: Case C-124/97, Läärä and Case C-67/98, Zenatti. Common Market Law Review 37, 991-1005 (2000)

11. Straetmans, G.: Case C-243/01, Piergiorgio Gambelli; and C-42/02 Diana Elisabeth Lindman. Common Market Law Review 41, 1409-1428 (2004)

12. Svenska Spel, Svenska Spel in Society 2005. Available at www.svenskaspel.se

13. Svenska Spel International - a partner in a regulated gaming market. Available at www.svenskaspel.se

14. Swiss Institute for Comparative Law, Study of Gambling Services in the Internal Market of the European Union, Final Report, 14 June 2006 (2006) 